\title{
Evaluation of the Impact of Laparoscopic Supracervical Hysterectomy for the Treatment of Adenomyosis on Pain Intensity and Patient Satisfaction
}

\author{
Garri Tchartchian ${ }^{*}$, Harald Krentel², Bernd Bojahr³, Rudy L. De Wilde ${ }^{4}$ \\ ${ }^{1}$ Clinic for Minimally Invasive Surgery, Berlin-Zehlendorf, Germany \\ ${ }^{2}$ Clinic for Women's Health and Obstetrics, St. Anna Hospital, Herne, Germany \\ ${ }^{3}$ Greifswald University Clinic, Clinic for Women's Health and Breast Center, Greifswald, Germany \\ ${ }^{4}$ Pius-Hospital, Clinic for Women's Health, Obstetrics and Gynecological Oncology, University Clinic for Gynecology, \\ Oldenburg, Germany \\ Email: *g.tchartchian@mic-berlin.de
}

How to cite this paper: Tchartchian, G., Krentel, H., Bojahr, B. and De Wilde, R.L. (2018) Evaluation of the Impact of Laparoscopic Supracervical Hysterectomy for the Treatment of Adenomyosis on Pain Intensity and Patient Satisfaction. Surgical Science, 9, 509-518.

https://doi.org/10.4236/ss.2018.912059

Received: October 23, 2018

Accepted: December 26, 2018

Published: December 29, 2018

Copyright $\odot 2018$ by authors and Scientific Research Publishing Inc. This work is licensed under the Creative Commons Attribution International License (CC BY 4.0).

http://creativecommons.org/licenses/by/4.0/

c) (i) Open Access

\begin{abstract}
Objectives. Common symptoms of adenomyosis include pain and bleeding disorders and can severely impact a patient's quality of life. Few studies report on the impact of hysteroscopy procedures on improving these symptoms. This study evaluates the effect of laparoscopic supracervical hysterectomy (LASH) in adenomyosis patients on pain in general, pain during intercourse, bleeding disorders and general satisfactoriness of the procedure. Methods. This prospective observational single-arm, single-center study included 256 patients treated with LASH and whose histological analysis revealed adenomyosis. Other inclusion criteria were completed family planning and no more symptom relief with conservative therapy. They completed questionnaires before and after the procedure which evaluated pain in general, pain during intercourse, bleeding disorders and general satisfactoriness of the procedure. Results. Our results showed a significant $(\mathrm{p}<0.0001)$ reduction of pain (from 1261 to 428 pain points), dyspareunia (from 763 to 224 pain points) and bleeding disorders when compared before and after LASH treatment. Furthermore, we found a high satisfaction rate of $98.4 \%$. Conclusion. As a minimal invasive procedure associated with low major complication rates, LASH is a qualified therapeutic choice to treat pain and bleeding disorders in adenomyosis patients with completed family planning and in where conservative therapy failed.
\end{abstract}

\section{Keywords}

Hysterectomy, Laparoscopy, Endometriosis, Adenomyosis, LASH, Pain 
Management

\section{Introduction}

Endometriosis is defined as the benign, ectopic growth of endometrial tissue, predominantly within the peritoneal cavity [1]. It mainly affects women of reproductive age, has a high recurrence rate and its pathogenesis is unclear [2]. Adenomyosis (previously called endometriosis interna) is a specific type of endometriosis where the ectopic endometrial growth occurs in the myometrium. Adenomyosis predominantly affects peri-menopausal and multiparous women [3]. Common, often debilitating, symptoms include abnormal bleeding (metrorrhagia), extreme and/or chronic pelvic pain, painful periods (dysmenorrhea), pain during intercourse (dyspareunia), as well as infertility. Approximately $20 \%-25 \%$ of patients experience no symptoms [4]. No specific biomarkers have been found so far, so current diagnosis is only possible via hysteroscopic or laparoscopic biopsy; non-invasive imaging can contribute to differential diagnosis [5]. Reports on the prevalence of adenomyosis vary widely from $1 \%-70 \%$, depending on the study population and the diagnostic criteria used. These major differences can be explained by the fact that signs and symptoms are unspecific and that diagnosis after hysterectomy is less convenient since the implementation of minimally invasive techniques often makes use of a morcellator, which complicates the determination of cell origin. Two different systematic reviews however, estimate the prevalence between $20 \%$ and $30 \%$ in the general female population while the prevalence in women with bleeding disorders is calculated as high as $50 \%$ [6] [7].

The impact on the quality of life of common adenomyosis symptoms, such as pain and bleeding disorders, is often quite severe. Current therapeutic strategies focus on relieving clinical symptoms and range from conservative medicinal approaches to definite complete hysterectomies [8]. The present study evaluates the effect of laparoscopic supracervical hysterectomy in adenomyosis patients on pain in general, pain during intercourse, bleeding disorders and general satisfactoriness of the procedure.

\section{Materials and Methods}

\subsection{Study Design}

This study is a prospective observational, single-arm, single-center study designed to assess the effect of laparoscopic assisted hysterectomy (LASH) on the severity of pain in general, pain during intercourse, and bleeding disorders as compared before and after surgery in patients with adenomyosis.

\subsection{Ethical Approval}

For the present study, no ethical approval is required in Germany. All patients 
were adequately informed about the details of the study and provided written informed consent before the procedure.

\subsection{Patients and Methods}

From January to December 2014, women who received LASH (performed as described in [9]) and whose histological analysis revealed adenomyosis, were included in this study. Other inclusion criteria were completed family planning and women who no longer experienced symptom relief with conservative therapy. As such, we obtained completed questionnaires from before and after the procedure of 256 women. The average demographics of study participants are shown in Table 1. The following parameters were compared before and after surgery: pain in general, pain during intercourse, and, bleeding disorders. We used the visual analog scale (VAS) to measure pain severity (Figure 1). When inquired whether they experienced bleeding, patients could choose between the following answers: "never", "once", "irregular" or "monthly". Patients were given the questionnaires right before surgery and again about a year after surgery to allow for enough time for follow-up and proper assessment of the questions asked. Furthermore, postoperative satisfactoriness of patients was evaluated as well. Patients could answer the question "How satisfied are you with your surgery?" with "Very satisfied", "Satisfied", "Partially Satisfied", and, "Not Satisfied".

\subsection{Statistical Analysis}

The results from the VAS were converted into numbers ranging between 0 and 10 where 0 indicates the absence of pain and 10 corresponds to unbearable pain. Values between 0 and 3, 4 and 6, 7 and 10 are classified as no to low pain, moderate pain and severe pain respectively. Data were analyzed using Windows-Excel (Microsoft 2010). Statistical analyses were performed using SPSS for Windows (SPSS 16.0, SPSS, Inc., Chicago, IL).

\section{Results}

Table 2 gives an overview of the results of the questionnaires completed by our study collective before and after LASH treatment.

\subsection{Pain in General}

255 subjects of our study group of 256 women (99.6\%) completed the questionnaire regarding pre- and postoperative pain experience. Before the LASH procedure, 89 adenomyosis women (34.8\%) indicated they experienced no to low pain while $64(25.0 \%)$ and $102(39.8 \%)$ women reported moderate and severe

Table 1. Demographic characteristics.

\begin{tabular}{ccc}
\hline Age (years) & Weight $(\mathrm{kg})$ & BMI \\
\hline 50.6 & 70.9 & 25.5 \\
\hline
\end{tabular}

Average demographics of the 256 patients from our study group. 
Table 2. Questionnaire outcome.

\begin{tabular}{|c|c|c|c|c|}
\hline & \multicolumn{2}{|c|}{ Before LASH } & \multicolumn{2}{|c|}{ After LASH } \\
\hline & $\mathrm{N}$ & $\%$ & $\mathbf{N}$ & $\%$ \\
\hline Pain in general (sum of pain points) & \multicolumn{2}{|c|}{1261} & \multicolumn{2}{|c|}{428} \\
\hline No to low pain & 89 & 34.8 & 211 & 82.0 \\
\hline Moderate pain & 64 & 25.0 & 32 & 12.5 \\
\hline Severe pain & 102 & 38.9 & 12 & 4.7 \\
\hline Pain during intercourse (sum of pain points) & \multicolumn{2}{|c|}{763} & \multicolumn{2}{|c|}{224} \\
\hline No to low pain & 142 & 55.5 & 231 & 90.2 \\
\hline Moderate pain & 57 & 22.3 & 11 & 4.3 \\
\hline Severe pain & 46 & 18.0 & 6 & 2.3 \\
\hline \multicolumn{5}{|l|}{ Bleeding disorders } \\
\hline Bleeding, impairing QOL & 177 & 69.1 & 92 & 35.9 \\
\hline No experience of bleeding & 77 & 30.0 & 160 & 62.5 \\
\hline \multicolumn{5}{|l|}{ Patient satisfaction with LASH procedure } \\
\hline Very satisfied & & & 196 & 76.6 \\
\hline Satisfied & & & 43 & 16.8 \\
\hline Partially satisfied & & & 13 & 5.1 \\
\hline Not satisfied & & & 4 & 1.6 \\
\hline
\end{tabular}

$($ LASH = Laparoscopic Supracervical Hysterectomy; QOL = Quality of Life).

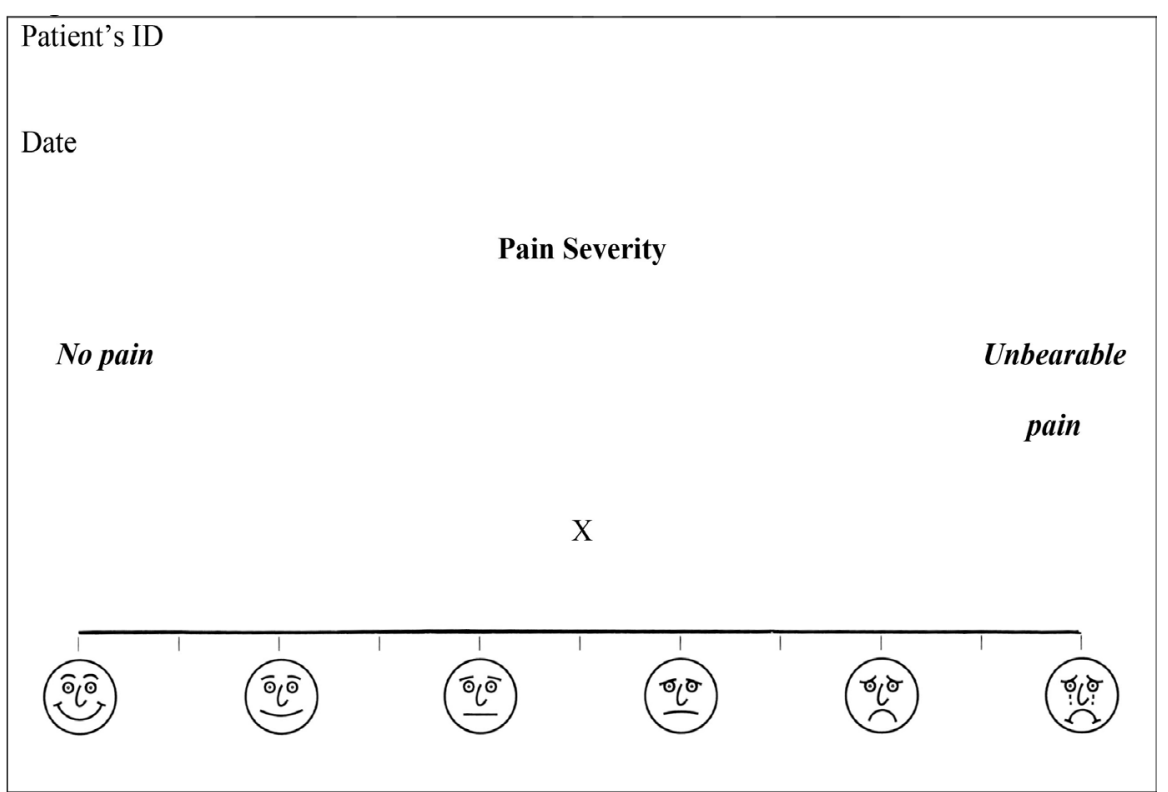

Figure 1. The Visual Analog Scale to evaluate pain severity. In our study, the Visual Analog Scale (VAS) was used as a tool for patients to subjectively answer the following three questions asked in our study (all three were asked both before and after surgery): "how intense and how frequent do you experience pain in general, pain during intercourse, and, bleeding disorders?" 
pain respectively. The sum of numeric values of the VAS regarding preoperative pain in our study group was 1261.

After surgery, 211 women (82.0\%) reported no to low pain, while only 32 (12.5\%) indicated experiencing moderate pain and merely 12 (4.7\%) reported severe pain. The sum of pain points in our patient collective dropped from 1261 before surgery to 428 after surgery $(\mathrm{p}<0.0001)$.

\subsection{Pain during Intercourse}

Patients were asked to complete a VAS to evaluate pain experience during intercourse before and after LASH treatment. 248 of 256 women (96.9\%) completed those questionnaires. Before the operation, 142 women (55.5\%) reported no to low dyspareunia whereas 57 (22.3\%) indicated experiencing moderate pain. $46(18.0 \%)$ of all women expressed to experience severe pain during sexual relations. After surgery, the number experiencing no to low pain during intercourse increased to $231(90.2 \%)$. Only 17 patients still reported dyspareunia after the LASH procedure of whom 11 (4.3\%) expressed moderate pain and six (2.3\%) severe pain. The sum of numeric values of the VAS evaluating dyspareunia dropped from 763 before LASH to 224 after LASH $(\mathrm{p}<0.0001)$.

\subsection{Bleeding Disorders}

Before LASH surgery, 177 patients (69.1\%) reported bleeding disorders which impaired their quality of life. 77 patients $(30.0 \%)$ did not experience bleeding whereas two patients were non-responders (99.2\% response rate).

After surgery, the number of patients without bleeding increased to 160 (62.5\%). 92 patients still reported bleeding disorders. Of those, 41 subjects (16\%) noticed only a single postoperative bleeding, 27 patients (10.5\%) reported irregular spotting, and, 24 subjects (9.4\%) still reported regular bleeding. Four patients did not answer the questions regarding postoperative bleeding $(98.4 \%$ response rate).

\subsection{Patient Satisfactoriness}

After LASH treatment, 196 patients (76.6\%) ticked the box "very satisfied", 43 (16.8\%) marked "satisfied“, and 13 (5.1\%) "partially satisfied". Taken together, this indicates that $98.4 \%$ of our patients collective were satisfied with LASH surgery. Four patients (1.6\%) reported to be "unsatisfied" with their treatment.

\section{Discussion}

Adenomyosis is affecting a considerable percentage of the female population and the often severe symptoms have a profound impact on women's quality of life. The optimal therapeutic choice should be defined individually, taking into account the intensity of symptoms, a possible future wish for pregnancy, the age and subsequent impact of preliminary menopausal state on a woman's life.

The first step in the non-surgical approach is the administration of painkillers 
(mainly NSAIDs). The most established medical therapy consists of gonadotropin-releasing hormone agonists (GnRHa). Studies show that GnRHa reduce pain, decrease uterus size and can even induce amenorrhea. They can only be taken during a period of up to six months because of their hypo-estrogenic side effects [10] [11] and when treatment is disrupted, women experience reappearance of the disease and its symptoms ([10] p. 12). Because adenomyosis and endometriosis are considered estrogen-dependent, aromatase inhibitors which inhibit the conversion of androgens into estrogens, are conservative options as well [11]. Both are also used after conservative surgery in order to reduce recurrence rates [12]. The continuous intake of oral contraceptives, both the progestin-only as the combined, has shown to relieve symptoms of adenomyosis and endometriosis in some women as well, since they induce amenorrhea. Some studies even suggest that their effect is similar to that of GnRHa with the advantage that they are less expensive, induce fewer side effects and can be administered for a longer period of time [13].

Uterine artery embolization (UAE) is an option for women who do not wish or are not suitable for surgical intervention [14]. The efficacy and the prevalence of serious side effects are similar as with hysterectomy procedures yet shorter convalescence is an obvious advantage. Nevertheless, even though the possibility of future pregnancies is not ruled out, tentative evidence suggests that UAE impairs fertility due to a higher risk of abnormal placentation. Moreover, more repeat surgeries are required as compared to traditional surgery [15]. MRI-assisted high intensity focused ultrasound ablation has been shown to be safe and effective for the treatment of uterine fibroids with the advantage of being less invasive than other procedures hence recovery periods are shorter. This treatment is time-consuming, the efficiency is significantly higher for women with distinctly localized adenomyosis foci and about $16 \%-20 \%$ of patients require additional treatment afterwards [16] [17].

The most definite approach is complete hysterectomy, yet, there is a tendency towards uterine-sparing interventions, in particular when there is a future wish for pregnancy. The latter methods focus on symptom relief, removal of endometriotic foci, and, prevention of the formation of new extra-uterine endometrial tissue. Those surgical options include endometrial ablation and excision of endometriotic foci in the myometrium. Because of unknown depth of adenomyotic penetration and difficult exposure of the foci in the myometrium, the recurrence rate with both procedures is high (reported up to 50\%). Furthermore, endometrial ablation induces a high risk of bleeding while foci excision leaves scars in the uterus, which could affect fertility [14] [18].

In the last decades, a gradual shift from abdominal hysterectomy procedures towards minimal invasive techniques occurred because of demonstrated advantages of the latter, such as minor trauma, improved aesthetic outcome, and, lower costs [9] [19] [20] [21]. Yet, as shown by many research groups, total laparoscopic hysterectomy is associated with a relatively high rate of major complications (between $4.5 \%$ and 5.8\%), in particular injuries to the urinary tract [22] 
[23]. In contrast, the incidence of major complications occurring with LASH is reported to be between $0.23 \%$ and $0.5 \%$ [23] [24] [25] [26].

All therapies have demonstrated positive effects in terms of symptom relief, but it is difficult to interpret results since most studies are retrospective and apply different methods to identify and quantify pain. Furthermore, chronic pelvic pain is often associated with issues in other organ systems besides the reproductive tract [27]. Both for symptom improvement and preventing disease recurrence, complete eradication of adenomyotic lesions is superior to medical treatment and sclerotherapy [28]. Approximately $12 \%$ of women with endometriosis will eventually require a hysterectomy to be relieved of symptoms [29]. According to clinical experience, definitive hysterectomy surgery accomplishes satisfactory alleviation of adenomyosis-associated pain. However, a recent study reports a $15 \%$ probability of persistent pain after standard hysterectomy with a $3 \%$ - 5\% risk of worsening pain or new symptom development [30].

We performed LASH on adenomyosis patients with no future wish for pregnancy and who no longer achieved symptom relief with conservative therapy. In our patient group of 256 patients, only 46 (17.9\%) reported an increase in pain in general, 22 (8.6\%) indicated increased pain during intercourse and $59(23 \%)$ reported increased bleeding disorders. Pain in general decreased significantly ( $\mathrm{p}$ $<0.001$ ) from 1261 to 428 pain points as compared before and after LASH. These results are similar as those of Berner et al. (2014) who investigated the impact of LASH on cyclic pelvic pain in 113 patients [31]. They found that only $32.4 \%$ of women in their study group still experienced this pain 12 months after surgery. Additionally, our evaluation also showed that pain during intercourse dropped significantly $(\mathrm{p}<0.001)$ from 763 to 224 pain points. Moreover, the number of patients who no longer experienced dyspareunia after surgery increased from 142 to 241 . As a result of LASH treatment, the number of patients suffering from bleeding disorders decreased from $69.1 \%$ to $35.9 \%$. Our study population showed a very high satisfaction rate of $98.4 \% .76 .6 \%$ of our patients indicated to be very satisfied with the LASH procedure, $16.8 \%$ of patients reported to be satisfied and $5.1 \%$ were partially satisfied.

Our results suggest that LASH is promising in being a method of choice for respective patients but more prospective randomized studies are needed to confirm this hypothesis as well as to compare with other hysterectomy procedures.

\section{Ethical Approval}

For this type of study formal consent is not required.

\section{Conflicts of Interest}

The authors declare that they have no conflict of interest.

\section{References}

[1] Ickey, M., Ballard, K. and Farquhar, C. (2014) Endometriosis. BMJ, 348, g1752. 
https://doi.org/10.1136/bmj.g1752

[2] Ahn, S.H., Monsanto, S.P., Miller, C., Singh, S.S., Thomas, R. and Tayade, C. (2015) Pathophysiology and Immune Dysfunction in Endometriosis. Biomed Res Int, 2015, Article ID 795976. https://doi.org/10.1155/2015/795976

[3] Senturk, L.M. and Imamoglu, M. (2015) Adenomyosis: What Is New? Women's Health (Lond), 11, 717-724. https://doi.org/10.2217/whe.15.60

[4] Bulletti, C., Coccia, M.E., Battistoni, S. and Borini, A. (2010) Endometriosis and Infertility. Journal of Assisted Reproduction and Genetics, 27, 441-447.

https://doi.org/10.1007/s10815-010-9436-1

[5] Struble, J., Reid, S. and Bedaiwy, M.A. (2016) Adenomyosis: A Clinical Review of a Challenging Gynecologic Condition. Journal of Minimally Invasive Gynecology, 23, 164-185. https://doi.org/10.1016/j.jmig.2015.09.018

[6] Vercellini, P., Vigano, P., Somigliana, E., Daguati, R., Abbiati, A. and Fedele, L. (2006) Adenomyosis: Epidemiological Factors. Best Practice \& Research Clinical Obstetrics \& Gynaecology, 20, 465-477. https://doi.org/10.1016/j.bpobgyn.2006.01.017

[7] Rabinovici, J. and Stewart, E.A. (2006) New Interventional Techniques for Adenomyosis. Best Practice \& Research Clinical Obstetrics \& Gynaecology, 20, 617-636. https://doi.org/10.1016/j.bpobgyn.2006.02.002

[8] Taran, F.A., Stewart, E.A. and Brucker, S. (2013) Adenomyosis: Epidemiology, Risk Factors, Clinical Phenotype and Surgical and Interventional Alternatives to Hysterectomy. Geburtshilfe Frauenheilkd, 73, 924-931. https://doi.org/10.1055/s-0033-1350840

[9] Tchartchian, G., Gardanis, K., Bojahr, B. and de Wilde, R.L. (2013) Postoperative Patient Satisfaction after Laparoscopic Supracervical Hysterectomy. JSLS: Journal of the Society of Laparoendoscopic Surgeons/Society of Laparoendoscopic Surgeons, 17, 107-110. https://doi.org/10.4293/108680812X13517013318067

[10] Fedele, L., Bianchi, S. and Frontino, G. (2008) Hormonal Treatments for Adenomyosis. Best Practice \& Research Clinical Obstetrics \& Gynaecology, 22, 333-339. https://doi.org/10.1016/j.bpobgyn.2007.07.006

[11] Badawy, A.M., Elnashar, A.M. and Mosbah, A.A. (2012) Aromatase Inhibitors or Gonadotropin-Releasing Hormone Agonists for the Management of Uterine Adenomyosis: A Randomized Controlled Trial. Acta Obstetricia et Gynecologica Scandinavica, 91, 489-495. https://doi.org/10.1111/j.1600-0412.2012.01350.x

[12] Farquhar, C. and Brosens, I. (2006) Medical and Surgical Management of Adenomyosis. Best Practice \& Research Clinical Obstetrics \& Gynaecology, 20, 603-616. https://doi.org/10.1016/j.bpobgyn.2006.01.012

[13] Schindler, A.E. (2013) Non-Contraceptive Benefits of Oral Hormonal Contraceptives. International Journal of Endocrinology \& Metabolism, 11, 41-47. https://doi.org/10.5812/ijem.4158

[14] Cockerham, A.Z. (2012) Adenomyosis: A Challenge in Clinical Gynecology. Journal of Midwifery \& Women's Health, 57, 212-220. https://doi.org/10.1111/j.1542-2011.2011.00117.x

[15] Gupta, J.K., Sinha, A., Lumsden, M.A. and Hickey, M. (2014) Uterine Artery Embolization for Symptomatic Uterine Fibroids. Cochrane Database of Systematic Reviews, No. 12, CD005073. https://doi.org/10.1002/14651858.CD005073.pub4

[16] Fischer, K., McDannold, N.J., Tempany, C.M., Jolesz, F.A. and Fennessy, F.M. (2015) Potential of Minimally Invasive Procedures in the Treatment of Uterine Fi- 
broids: A Focus on Magnetic Resonance-Guided Focused Ultrasound Therapy. International Journal of Women's Health, 7, 901-912.

[17] Zhang, X., Li, K., Xie, B., He, M., He, J. and Zhang, L. (2014) Effective Ablation Therapy of Adenomyosis with Ultrasound-Guided High-Intensity Focused Ultrasound. International Journal of Gynecology \& Obstetrics, 124, 207-211. https://doi.org/10.1016/j.ijgo.2013.08.022

[18] Garcia, L. and Isaacson, K. (2011) Adenomyosis: Review of the Literature. Journal of Minimally Invasive Gynecology, 18, 428-437. https://doi.org/10.1016/j.jmig.2011.04.004

[19] Mourits, M.J., Bijen, C.B., Arts, H.J., ter Brugge, H.G., van der Sijde, R., Paulsen, L., Wijma, J., Bongers, M.Y., Post, W.J., van der Zee, A.G. and de Bock, G.H. (2010) Safety of Laparoscopy versus Laparotomy in Early-Stage Endometrial Cancer: A Randomised Trial. The Lancet Oncology, 11, 763-771. https://doi.org/10.1016/S1470-2045(10)70143-1

[20] Tchartchian, G., Heldmann, P., Bojahr, B., Larbig, A. and De Wilde, R.L. (2017) The Laparoscopic-Assisted Combined Hysterectomy: A New Surgical Concept Compared to the Classical Laparoscopic-Assisted Vaginal Hysterectomy by a Prospective Study. Gynecologic and Obstetric Investigation, 82, 223-229. https://doi.org/10.1159/000447592

[21] Tchartchian, G., Dietzel, J., Bojahr, B., Hackethal, A. and De Wilde, R.L. (2010) No More Abdominal Hysterectomy for Myomata Using a New Minimally-Invasive Technique. International Journal of Surgery Case Reports, 1, 7-8. https://doi.org/10.1016/j.ijscr.2010.06.001

[22] Morelli, M., Caruso, M., Noia, R., Chiodo, D., Cosco, C., Lucia, E., Biamonte, M. and Zullo, F. (2007) Total Laparoscopic Hysterectomy versus Vaginal Hysterectomy: A Prospective Randomized Trial. Minerva Ginecologica, 59, 99-105.

[23] Garry, R., Fountain, J., Brown, J., Manca, A., Mason, S., Sculpher, M., Napp, V., Bridgman, S., Gray, J. and Lilford, R. (2004) Evaluate Hysterectomy Trial: A Multicentre Randomised Trial Comparing Abdominal, Vaginal and Laparoscopic Methods of Hysterectomy. Health Technology Assessment, 8, 1-154. https://doi.org/10.3310/hta8260

[24] Bojahr, B., Raatz, D., Schonleber, G., Abri, C. and Ohlinger, R. (2006) Perioperative Complication Rate in 1706 Patients after a Standardized Laparoscopic Supracervical Hysterectomy Technique. Journal of Minimally Invasive Gynecology, 13, 183-189. https://doi.org/10.1016/j.jmig.2006.01.010

[25] Harmanli, O.H., Tunitsky, E., Esin, S., Citil, A. and Knee, A. (2009) A Comparison of Short-Term Outcomes between Laparoscopic Supracervical and Total Hysterectomy. American Journal of Obstetrics and Gynecology, 201, 536e531-537. https://doi.org/10.1016/j.ajog.2009.07.048

[26] Bojahr, B., De Wilde, R.L. and Tchartchian, G. (2015) Malignancy Rate of 10,731 Uteri Morcellated during Laparoscopic Supracervical Hysterectomy (LASH). Archives of Gynecology and Obstetrics, 292, 665-672.

https://doi.org/10.1007/s00404-015-3696-Z

[27] Practice Committee of American Society for Reproductive M (2008) Treatment of Pelvic Pain Associated with Endometriosis. Fertility and Sterility, 90, S260-S269. https://doi.org/10.1016/j.fertnstert.2008.08.057

[28] Duffy, J.M., Arambage, K., Correa, F.J., Olive, D., Farquhar, C., Garry, R., Barlow, D.H. and Jacobson, T.Z. (2014) Laparoscopic Surgery for Endometriosis. Cochrane Database of Systematic Reviews, No. 4, CD011031. 
https://doi.org/10.1002/14651858.CD011031

[29] Rizk BA, H. (2003) Fast Facts: Endometriosis. 2nd Edition, Health Press, Oxford.

[30] Vercellini, P., Barbara, G., Abbiati, A., Somigliana, E., Vigano, P. and Fedele, L. (2009) Repetitive Surgery for Recurrent Symptomatic Endometriosis: What to Do? European Journal of Obstetrics \& Gynecology and Reproductive Biology, 146, 15-21. https://doi.org/10.1016/j.ejogrb.2009.05.007

[31] Berner, E., Qvigstad, E., Myrvold, A.K. and Lieng, M. (2014) Pelvic Pain and Patient Satisfaction after Laparoscopic Supracervical Hysterectomy: Prospective Trial. Journal of Minimally Invasive Gynecology, 21, 406-411.

https://doi.org/10.1016/j.jmig.2013.10.011 